\title{
Evaluation of Patients with Blunt Abdominal Injuries by Ultrasonography and Multidetector Computed Tomography.
}

\author{
Ravi Kiran $\mathrm{G}^{1}$, Harshavardhan $\mathrm{NS}^{2}$, Anil U Madurwar ${ }^{3}$, Santhosh $\mathrm{D}^{4}$ \\ ${ }^{1}$ Asst. Professor, Department of Radio-Diagnosis, Chalmeda Anand Rao Institute of Medical Sciences, Karimnagar-505001, ${ }^{2}$ Associate Professor, Department of \\ Radio-Diagnosis, Chalmeda Anand Rao Institute of Medical Sciences, Karimnagar-505001, ${ }^{3}$ Professor, Department of Radio-Diagnosis, Chalmeda AnandRao \\ Institute of Medical Sciences, Karimnagar-505001, ${ }^{4}$ PG Student, Department of Radio-Diagnosis, Chalmeda AnandRao Institute of Medical Sciences, Karimnagar- \\ 505001
}

\section{Abstract}

Background: Blunt abdominal trauma (BAT) usually occurs due to road traffic accidents (RTA), fall from heights or during sports. Prevalence of intraabdominal injury varies widely, ranging from $7.7 \%$ to $65 \%$. The aim of study was to evaluate the role of ultrasonography (USG) \& multi-detector computed tomography (MDCT) in identifying intra abdominal injury in patients with blunt abdominal trauma and to compare-provide information that could accurately determine choice of management (non-operative vs operative). Subjects and Methods: This study was a prospective study; total 50 patients were included in this study. This study was conducted at Department of RadioDiagnosis, Chalmeda AnandRao Institute of Medical Sciences, Karimagar. The study period was during from October 2015 to September 2017. USG examinations were performed with a curvilinear and linear probe on GE Voluson S6\& Philips Envisor C HD. Results: A total of 38 cases were positive for intra abdominal injury and 12 cases were negative for intra abdominal injury. 30 patients underwent surgery and the remaining cases were managed conservatively. Most of the patients admitted to this hospital were victims of vehicular accidents. Road traffic accidents (RTAs) as accounting for 33 cases $(66 \%)$ of the blunt abdominal trauma. Conclusion: The present study concluded that MDCT is the superior diagnostic modality in the diagnosis of blunt abdominal trauma. USG can be a valuable initial investigation; however, USG can miss crucial injuries and may lead to inappropriate management in some patients.

Keywords: Blunt abdominal injuries, ultrasonography, multidetector computed tomography.

Corresponding Author: Dr. Harshavardhan NS, MD (Radio-Diagnosis), Assoc. Professor, Department of Radio-Diagnosis, Chalmeda AnandRao Institute of Medical SciencesKarimnagar-505001, Telangana.

Received: January 2019

Accepted: February 2019

\section{Introduction}

Blunt abdominal trauma (BAT) usually occurs due to road traffic accidents (RTA), fall from heights or during sports. Prevalence of intra abdominal injury varies widely, ranging from $7.7 \%$ to $65 \% .{ }^{[1]}$ The Indian fatality rates for trauma are 20 times that for developed countries. About $30 \%$ of such deaths are thought to be preventable. ${ }^{[2]}$

CT of the abdomen can depict such injuries accurately and is relatively noninvasive. CT as the sole modality enables evaluation of other associated injuries in addition to global evaluation of abdominal trauma in hemodynamically stable patients and is extensively used in North American centers as the initial modality of diagnosis. ${ }^{[3]}$

During past several years, Ultrasonography (USG) has become an important modality in many centers in the screening of blunt abdominal trauma.USG is the primary imaging modality of choice for diagnosis of intra abdominal injury. It is non invasive, rapid, relatively inexpensive and a reliable diagnostic tool for assessment of presence of abdominal fluid and in detecting liver, spleen and kidney injuries.

The purpose of this study was to evaluate the role of USG
\& MDCT in identifying intra abdominal injury in patients with blunt abdominal trauma and to compare provide information that could accurately determine choice of management (non-operative vs operative).

\section{Subjects and Methods}

This study was a prospective study; total 50 patients with blunt abdominal trauma were included in this study. This study was conducted at Department of Radio-Diagnosis, Chalmeda AnandRao Institute of Medical Sciences, Karimnagar. The study duration was October 2015 to September 2017.

\section{Inclusion Criteria:}

1. All the patients irrespective of age and sex

2. history of blunt abdominal trauma

Exclusion criteria

1. Patients who were hemodynamically unstable.

2. Pregnant women.

3. Penetrating injuries.

Technique of Ultrasound:

USG examinations were performed with a curvilinear and 


\section{Firan et al; Evaluation of Patients with Blunt Cledaminal Injuries}

linear probe on GE Voluson S6\& Philips Envisor C HD. The presence of free fluid within the abdominal cavity was accepted as a positive sign for hemoperitoneum. Visceral organs were evaluated for parenchymal abnormalities consisting of intraparenchymal hematomas, lacerations, and/or geographic zones of echotextural heterogeneity.

\section{Technique for CT}

All CT scans were obtained with routine antero-posterior tomogram of the abdomen was initially taken in all patients in the supine position. Axial sections of $5 \mathrm{~mm}$ thickness was taken from the level of lung bases to the level of ischial tuberosities. Kilovolt peak: 120-140 kvp, Milli ampere second: 200-250 mAs for an average sized patient (increased values for oversized patients). Pitch: 1.5, Field of view: 240-350 mm; Collimation: $2.5 \mathrm{~mm}$, Matrix size: $512 \times 512$

Plain scans were followed by intravenous contrast scans. For intravenous contrast enhancement, 80-100 $\mathrm{ml}$ of dynamic injection of (Iversol-300 $\mathrm{mg}$ of iodine per $\mathrm{ml}$ ) or in children a dose of $300 \mathrm{mg}$ of iodine $/ \mathrm{Kg}$ body wt was administered and axial sections were taken. Sections were taken in arterial (30sec) and portal venous (60-90sec) phases. Delayed scanning (5-7min) was not routinely performed, only in suspected cases of renal or bladder traumas

Post study reconstructions were done at $2.5 \mathrm{~mm}$. Sagittal and Coronal reconstructions were made wherever necessary. The scans were viewed on a direct display console at multiple window settings (i.e abdomen window at 320/40; Lung window at 1400/-600; Bone window of 2400/200).

\section{Ethics Approval:}

This study was approved by Institute Ethics committee, Chalmeda AnandRao Institute of Medical Sciences, Karimnagar.

\section{Results}

The study included 50 patients with history of blunt abdominal injury who had all undergone both USG and MDCT. A total of 38 cases were positive for intraabdominal injury and 12 cases were negative for intraabdominal injury. 30 patients underwent surgery and the remaining cases were managed conservatively.

The age group of the patients was very wide, ranging from 5-80 years. Most commonly affected age group was 21-40 years [Table 1].

The male to female ratio was $42: 8$ with predominate male preponderance. [Table 2].

Most of the patients admitted to this hospital were victims of vehicular accidents. Road traffic accidents (RTAs) as accounting for 33 cases $(66 \%)$ of the blunt abdominal trauma. The other causes were, accidental fall from a height, hit by a projectile object \& few cases of assault. [Table 3]

In this study, the commonest organs affected were the spleen (14 cases) and liver (11 cases) accounting for 33\% and $26 \%$ respectively. Third most common was Hollow viscus injury (10 cases) accounting for $23 \%$. There were 2 cases of mesenteric tear, 3 cases of renal trauma, 1 case of pancreatic trauma, 1 case of urinary bladder trauma and 1 case of vascular injury. [Table 5]

\begin{tabular}{l}
\hline Table 1: Age distribution. \\
\begin{tabular}{|c|c|}
\hline Age group in years & No. of patients (Percentage) \\
\hline $01-20$ & $07(14 \%)$ \\
\hline $21-40$ & $32(64 \%)$ \\
\hline $41-60$ & $08(16 \%)$ \\
\hline $61-80$ & $03(06 \%)$ \\
\hline
\end{tabular}
\end{tabular}

Table 2: Sex distribution

\begin{tabular}{|c|c|}
\hline Sex & Percentage \\
\hline Male & $84 \%$ \\
\hline Female & $16 \%$ \\
\hline
\end{tabular}

Table 3: Mode of Injury

\begin{tabular}{|l|l|}
\hline Mode of Injury & No. of patients (Percentage) \\
\hline RTA & $33(66 \%)$ \\
\hline Fall from Heights & $5(10 \%)$ \\
\hline Automobile Vs pedestrian & $5(10 \%)$ \\
\hline $\begin{array}{l}\text { Assault Others(Bull horn injury, Hit } \\
\text { by a projectile object }\end{array}$ & $3(6 \%)$ \\
\hline $\begin{array}{l}\text { Others(Bull horn injury, Hit by a } \\
\text { projectile object }\end{array}$ & $4(8 \%)$ \\
\hline
\end{tabular}

Table 4: Distribution of organ injuries (n-38)

\begin{tabular}{|l|l|}
\hline Organ injured & Percentage \\
\hline Spleen & $33 \%$ \\
\hline Liver & $26 \%$ \\
\hline Hollow viscous & $23 \%$ \\
\hline Kidneys & $7 \%$ \\
\hline Mesentery & $5 \%$ \\
\hline Pancreas & $2 \%$ \\
\hline Urinary bladder & $2 \%$ \\
\hline Vascular injury & $2 \%$ \\
\hline
\end{tabular}

[Table 4] showed, a total of 43 organ injuries were noted in 38 patients. Most common injured organ is spleen (33\%). 6 cases showed multi-organ injuries.

Table 5: Comparison of USG diagnosis with operative diagnosis in solid organ injuries (n-21)

\begin{tabular}{|c|c|c|c|}
\hline USG & $\begin{array}{l}\text { Positive for solid } \\
\text { organ injury }\end{array}$ & $\begin{array}{l}\text { Negative for } \\
\text { solid organ } \\
\text { injury }\end{array}$ & Total \\
\hline $\begin{array}{l}\text { Positive for solid } \\
\text { organ injury }\end{array}$ & $11(\mathrm{TP})$ & $02(\mathrm{FP})$ & 13 \\
\hline $\begin{array}{l}\text { Negative for } \\
\text { solid organ } \\
\text { injury }\end{array}$ & $03(\mathrm{FN})$ & $05(\mathrm{FN})$ & 08 \\
\hline Total & 14 & 07 & 21 \\
\hline
\end{tabular}

Injury of the bowel and mesentery was not identified directly by USG, but identification of free intraperitoneal fluid with no evidence of solid visceral injury indicated a bowel injury. This was confirmed by MDCT which demonstrated free intraperitoneal air. Surgery revealed jejunal and ileal tears.

USG findings were compared to MDCT and laparotomy findings. USG results after comparison with operative 
Firan et al; Evaluation of Patients with Blunt Cledaminal Injuries

findings revealed that 11 were true positive, 2 were false positive, 5 true negative, and 3 false negative. [Table 6]

Table 6: Comparison of MDCT Diagnosis with operative diagnosis (n-30)

\begin{tabular}{|l|l|l|l|}
\hline MDCT & $\begin{array}{l}\text { Positive for } \\
\text { organ injury }\end{array}$ & $\begin{array}{l}\text { Negative } \\
\text { organ } \\
\text { injury }\end{array}$ & Total \\
\hline $\begin{array}{l}\text { Positive for organ } \\
\text { injury }\end{array}$ & $24(\mathrm{TP})$ & $01(\mathrm{FP})$ & 25 \\
\hline $\begin{array}{l}\text { Negative for organ } \\
\text { injury }\end{array}$ & $02(\mathrm{FN})$ & $03(\mathrm{TN})$ & 05 \\
\hline Total & 26 & 04 & 30 \\
\hline
\end{tabular}

FP-1 ligamentum teres was mistaken for a liver laceration in one case.

FN-2 cases of mesenteric tear were not detected on MDCT

MDCT correlated well with surgical findings in all 30 operated cases. In two cases, mesenteric tear was seen at laparotomy, which could not be detected at MDCT scan. MDCT results after comparison with operative findings revealed that 24 were true positive, 1 was false positive, 3 true negative, and 2 false negative.

Hemo peritoneum was observed on MDC' in 28 cases. USG detected free fluid in 27 patients. On MDCT 2 out of these 27 patients were labeled as negative for IAI (false positive) as free fluid was found to be ascitic fluid based on HU on MDCT. 3 cases of Hemoperitoneum were not detected on USG as free fluid developed later on as there was time gap between performing USG and MDCT. [Table 7]

Table 7: Comparison of USG diagnosis with MDCT diagnosis in Hemoperitoneum (N-50)

\begin{tabular}{|l|l|l|l|}
\hline \multicolumn{1}{|c|}{ USG } & $\begin{array}{l}\text { Positive for } \\
\text { Hemoperitoneum }\end{array}$ & $\begin{array}{l}\text { Negative for } \\
\text { Hemoperitoneum }\end{array}$ & Total \\
\hline $\begin{array}{l}\text { Positive for } \\
\text { Hemperitoneum }\end{array}$ & $25(\mathrm{TP})$ & $02(\mathrm{FP})$ & 25 \\
\hline $\begin{array}{l}\text { Negative for } \\
\text { Hemperitoneum }\end{array}$ & $03(\mathrm{FN})$ & $20(\mathrm{TN})$ & 05 \\
\hline Total & 28 & 22 & 50 \\
\hline
\end{tabular}

FP: 2 cases of $\Delta$ scitic fluid were mistaken for Hemoperitoneum.

FN: 3 cases of Hemoperitoneum were not detected on USG as free fluid developed later on because of time gap between performing USG \& MDCT

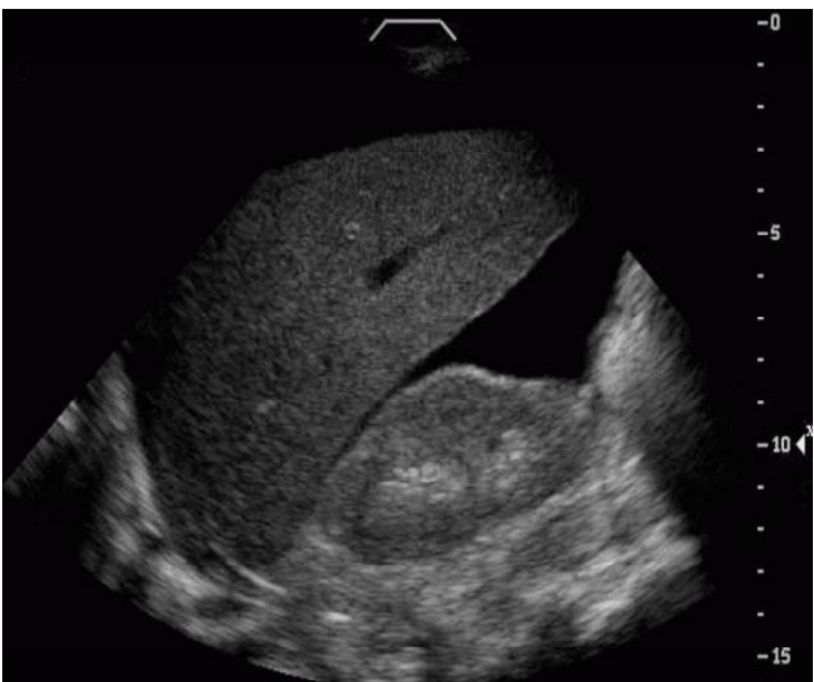

Figure 1: USG Abdomen showing free fluid in morrison's pouch.

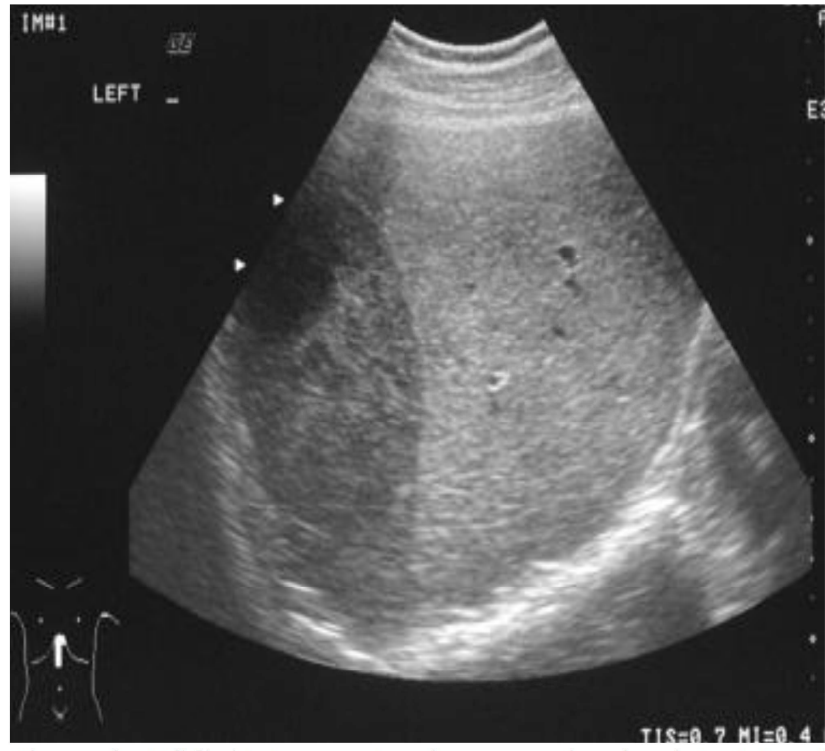

Figure 2: USG Abdomen showing contusion in right lobe of liver.

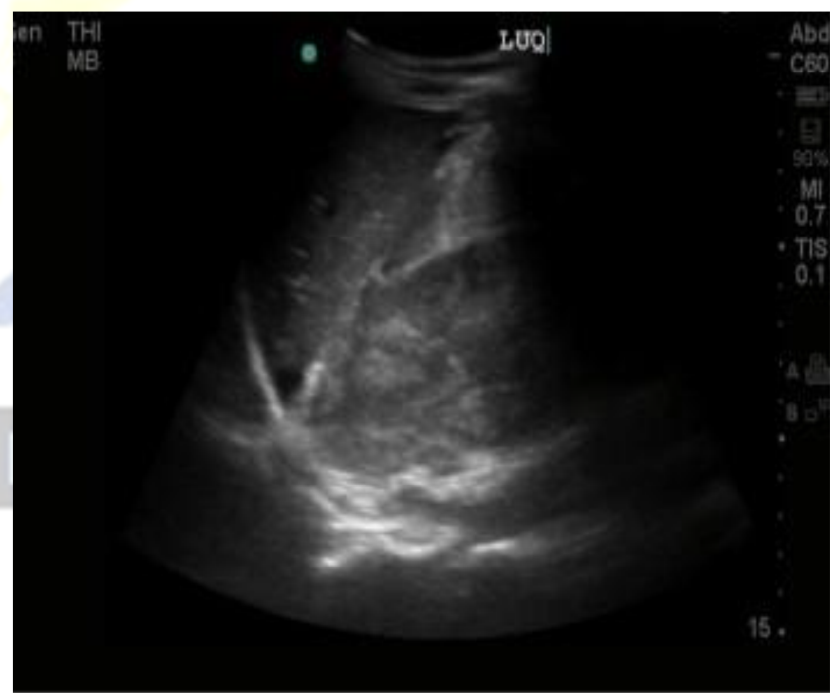

Figure 3: USG Abdomen showing contusion in right kidney.

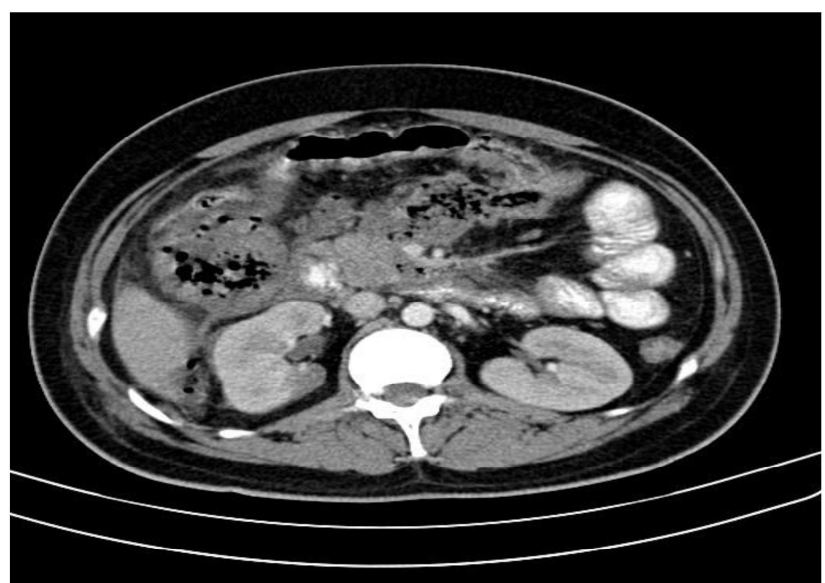

Figure 4: CECT Abdomen axial image at the level of kidneys showing contusion at midpole of right kidney 


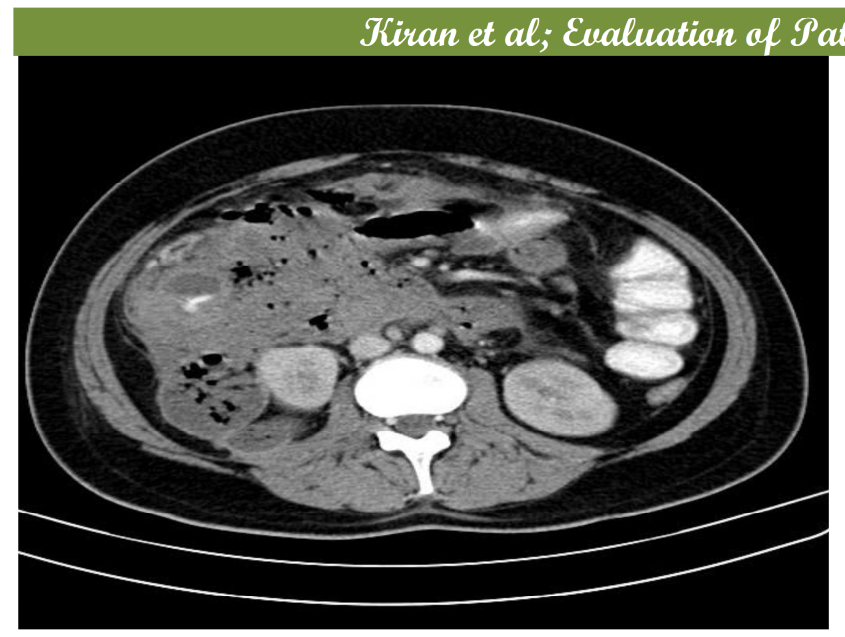

Figure 4: CECT Abdomen axial image at the level of kidneys showing mesenteric injury

\section{Discussion}

In this study, the maximum of patients $(64 \%)$ were in the age range of 21 to 40 years. Majority of these patients $(66 \%)$ were involved in motor vehicle accidents. Out of 50 patients in this study, $76 \%$ (38 patients) were positive for abdominal injury and 24\% (12 patients) were negative. Six patients sustained polytrauma with injuries involving more than one viscera or system. There was one death in this study.

This study was showed, out of $76 \%$ (38 patients) who were positive for intra-abdominal injury, 73.7\% (28 patients) had hemoperitoneum. The most frequent cause of blunt abdominal injury in the present study was road traffic accident which is in accordance with a study by Mallik K et al. ${ }^{[2]}$ Out of 34 positive cases on USG, 32 patients (94\%) were confirmed on MDCT as Intra-abdominal injury.

In the current study, we observed that both ultrasound and CT are highly sensitive in the detection of hemoperitoneum and organs injury with CT being slightly better in its diagnostic efficacy. This is similar to other studies reported in the literature. ${ }^{[4-6]}$

In the present study, USG detected free fluid in 27 patients. On MDCT 2 out of these 27 patients were labeled as negative for IAI (false positive) as free fluid was found to be ascitic fluid based on HU on MDCT. 3 cases of hemoperitoneum were not detected on USG as free fluid developed later on as there was time gap between performing USG and MDCT.

Richards et al study showed that total 744 patients, out of 51 patients who had free fluid identified by USG, 9 were false positive results; of these 9 patients 7 were female who had pelvic free fluid. Hence, most of these false positive results were reported to be originating from the physiological fluid observed in females. ${ }^{[7]}$ Several other authors also advocate conservative management of solid organ injury resulting from blunt abdominal trauma. ${ }^{[8]}$

In our study found that overall likelihood of surgical management increased with higher OIS grading of solid organ injury, as in the present study, 11 of 21 operated patients had grade 3 and 10 of 21 had grade 4 injuries.

\section{Conclusion}

The present study concluded that MDCT is the supcrior diagnostic modality in the diagnosis of blunt abdominal trauma. USG can be a valuable initial investigation; however, USG can miss crucial injuries and may lead to inappropriate management in some patients. Hence it is imperative that all USG positive cases should be followed by MDCT. Similarly MDCT must also be performed in symptomatic patients with negative USG scans and in patients with suboptimal USG scans.

\section{References}

1. Atif Latif, Muhammad Ashraf Farooq, Muhammad Adeel Azhar. Diagnostic Value of Ultrasonography in Evaluation of Blunt Abdominal Trauma. Rawal Med J. 2008; 33:154-159.

2. Mallik K, Vashisht S, Thakur S, Srivastava DN. Comparative evaluation of ultrasonography and $\mathrm{CT}$ in patients with abdominal trauma: A prospective study. Indian J Radiol Imaging. 2000; 10:23743.

3. Kumar MM, Venkataramanappa M, Venkatrathnam I et al. Prospective evaluation of Blunt abdominal trauma by CT. IJRI 2005; 15: 2:167-173.

4. Thourani VH, Pettitt BJ, Schmidt JA, Cooper WA, Rozycki GS Validation of surgeon performed emergency abdominal ultrasonography in pediatric trauma patients. J Pediatr Surg. 1998; 33:322-8.

5. Retzlaff T, Hirsch W, Till H, Rolle U. Is sonography reliable for the diagnosis of pediatric blunt abdominal trauma? J Pediatr Surg. 2010; 45:912-5-8.

6. Taş F, Ceran C, Atalar MH, Bulut S, Selbeş B, Ișik AO. The efficacy of ultrasonography in hemodynamically stable children with blunt abdominal trauma: A prospective comparison with computed tomography. Eur J Radiol. 2004; 51:91-6.

7. Richards JR, Nicolette A, Knopf A, Wang L, MaGahan JP. Blunt abdominal trauma in children: Evaluation with emergency US. Radiol. 2002; 222: 749-754.

8. Ozturk H, Dokucu AI, Onen A, Et Al. Non-operative management of isolated solid organ injuries owing to blunt abdominal trauma. Eur J Pediatr Surg. 2004; 14:29-34.

Copyright: (c) the author(s), publisher. Asian Journal of Medical Radiological Research is an Official Publication of "Society for Health Care \& Research Development". It is an open-access article distributed under the terms of the Creative Commons Attribution Non-Commercial License, which permits unrestricted non-commercial use, distribution, and reproduction in any medium, provided the original work is properly cited.

How to cite this article: Kiran GR, Harshavardhan NS, Madurwar AU, Santhosh D. Evaluation of Patients with Blunt Abdominal Injuries by Ultrasonography and Multidetector Computed Tomography. Asian J. Med. Radiol. Res. 2019;7(1):05-08.

DOI: dx.doi.org/10.21276/ajmrr.2019.7.1.2 